\title{
Compañías teatrales, manipulación textual y autoría literaria (a propósito de la lengua de Lope ${ }^{\top}$

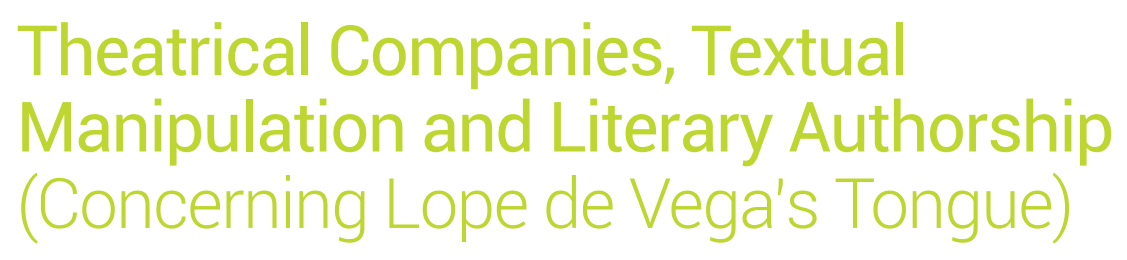

\section{Daniel Fernández Rodríguez}

Universitat Autònoma de Barcelona

ESPAÑA

daniel.fernandez@uab.es

[Hipogrifo, (issn: 2328-1308), 4.2, 2016, pp. 197-217]

Recibido: 10-02-2016 / Aceptado: 11-03-2016

DOI: http://dx.doi.org/10.13035/H.2016.04.02.15

Resumen. En este artículo se estudia la presencia y el uso de las palabras do, vide y vido en la obra de Lope de Vega, a partir de los datos obtenidos en veintisiete ediciones críticas basadas en autógrafos lopescos. El restringido y particular modo con que Lope empleó estos términos permite identificar pasajes de diferentes comedias que a todas luces fueron manipulados por una mano ajena al poeta, probablemente la de los directores de compañías. A partir de estos ejemplos, el artículo reflexiona acerca de la validez y los límites del análisis del vocabulario como método para abordar la autoría de una comedia del Siglo de Oro, así como sobre la necesidad de acometer su estudio a la hora de elaborar una edición crítica.

Palabras clave. Problemas de autoría, atribución literaria, compañías teatrales, ediciones críticas, vocabulario, Lope de Vega.

Abstract. In this paper I will study the presence and use of the words do, vide y vido in Lope de Vega's works, by analyzing twenty seven critical editions based on Lopean holographs. The restricted and particular way in which Lope used these

1. Este artículo se ha beneficiado de una beca FPU del Ministerio de Educación y de mi participación en el proyecto «Edición y estudio de 36 comedias de Lope de Vega» (FFI2015-66216-P), financiado por el Ministerio de Economía y Competitividad. 
terms will allow me to identify passages from different plays that were surely manipulated, probably by directors of theatrical companies. By studying these examples, I will think about the need to analyze the vocabulary in order to prepare a critical edition and about the reliability and limits of the vocabulary as a method for determining the authorship of a Golden Age comedia.

Keywords. Authorship Problems, Literary Attribution, Theatrical Companies, Critical Editions, Vocabulary, Lope de Vega.

Lope de Vega lamentó a menudo las nefastas consecuencias de los vaivenes y el trasiego, por corrales e imprentas, de sus textos teatrales. En la epístola «Al contador Gaspar de Barrionuevo», se quejaba del profundo deterioro de Las comedias del famoso poeta Lope de Vega Carpio, recopiladas por Bernardo Grasa (1604), o Parte primera, libro impreso en Zaragoza en los talleres de Angelo Tavanno: «Veréis en mis comedias (por lo menos / en unas que han salido en Zaragoza) / a seis renglones míos ciento ajenos»². En el «Prólogo» a la Parte novena, el dramaturgo madrileño nos advierte de los problemas críticos y teóricos que puede acarrear el proceso de transmisión de nuestro teatro clásico en todo cuanto atañe a la polémica cuestión de las autorías dramáticas: «Viendo imprimir cada día mis comedias, de suerte que era imposible llamarlas mías»³.

Lope no exagera un ápice. En el Siglo de Oro, una comedia impresa era el producto final de una larga serie de intervenciones textuales, un rimero de estratos que se superponían al texto originalmente escrito por el poeta, que incluso podía llegar a perder cualquier tipo de derecho sobre sus autógrafos al venderlos a los directores de las compañías. No por casualidad, a estos se les conocía como autores de comedias, denominación que «subraya con la fuerza de la semántica el carácter decisivo de sus operaciones sobre el texto literario» ${ }^{4}$. Los directores sabían al dedillo las características de su compañía y los gustos del público, y gozaban de plena libertad para manipular el texto a su antojo: «si a mano viene, arregla el texto, lo acorta o lo alarga: tiene siempre a sus órdenes un remendón de textos literarios» ${ }^{5}$. Su autoridad era tal que los poetas no puntuaban los autógrafos dramáticos (al contrario que los demás géneros), fiándoles a los autores de comedias «el ritmo de la entonación y de la cadencia del verso».

En el proceso de transmisión podían intervenir también los llamados memorillas o memoriones, expertos en memorizar -con no pocos deslices, claro- las obras que oían representar sobre las tablas ${ }^{7}$. Finalmente, los textos pasaban por manos de copistas e impresores, hecho que multiplicaba los errores y variantes. $Y$

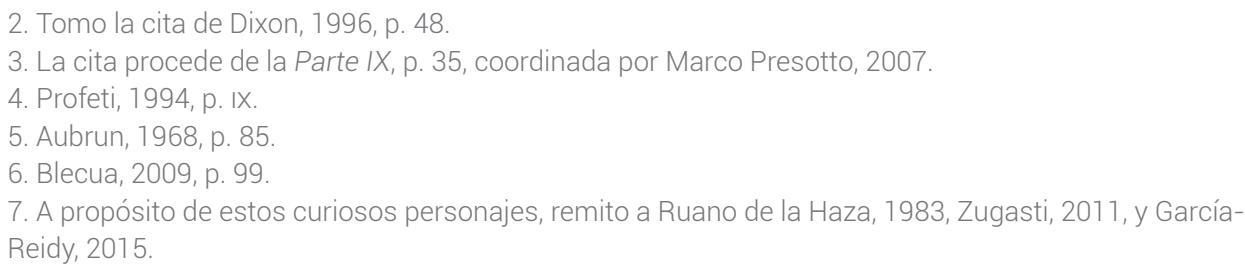


todo ello sin olvidar la censura previa a las representaciones que a menudo debían sortear los autógrafos. No en vano, Gonzalo Pontón ha advertido cómo «la particular transmisión del texto dramático permite afirmar que, en cierto modo, este estado proteico le es inherente» ${ }^{8}$.

$\mathrm{Ni}$ que decir tiene que las vicisitudes del negocio teatral dificultan sobremanera la labor de los filólogos interesados en realizar una edición crítica de una comedia del Siglo de Oro y en enfrentarse a cuestiones de autoría. En este artículo me centraré en el vocabulario, una de las herramientas empleadas por la crítica en el análisis de las atribuciones literarias, que nos servirá para identificar fragmentos a todas luces manipulados por manos ajenas a Lope y, confío, para saber un poco más acerca de la lengua lopesca y para ejemplificar los problemas textuales que implica la transmisión del teatro áureo.

Tomemos, para empezar, una humilde palabra del diccionario: el adverbio do. A mediados del siglo pasado, Fichter apuntó en una nota que Lope parece recurrir a dicho término en menor medida que otros poetas de su tiempo:

Doubtless a few other examples might be found in the remaining autographs, just as there is an occasional example in the Partes or other printed texts of Lopean plays. However, all the evidence gathered so far indicates that Lope used the word most sparingly -much more so than some of his contemporaries? ${ }^{9}$.

En quince autógrafos de Lope, Fichter solo encontró la palabra do en dos ocasiones, una en el estribillo «¿De dó viene, de dó viene?», de La dama boba (v. 2241), y otra en la expresión «¿De dó bueno?», de La prueba de los amigos (v. 2279) ${ }^{10}$. Por mi parte, he examinado el texto de veintisiete ediciones críticas basadas en autógrafos de Lope ${ }^{11}$, y solo he encontrado un caso más en El primero Benavides: «PAYO ¿De dó vienes? FERNÁN De León» (v. 3059)12. Cosa muy distinta son los casos en los que el adverbio do se emplea para caracterizar el habla dialectal de algún personaje (un villano, un pastor), o en los que forma parte de un texto incrustado en una comedia (un romance, una cancioncilla, etc.). Si bien no he encontrado ninguno en las

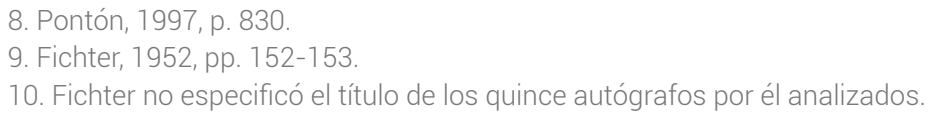
final, son los siguientes: La batalla del honor, Las bizarrías de Belisa, La buena guarda, La burgalesa de Lerma, El caballero del sacramento, El cardenal de Belén, Carlos V en Francia, El castigo sin venganza, El cordobés valeroso Pedro Carbonero, La corona merecida, El cuerdo loco, La dama boba, ¿De cuándo acá nos vino?, Del monte sale quien el monte quema, La doncella Teodor, Estefanía la desdichada, El favor agradecido, El galán de la Membrilla, La hermosa Ester, La mayor virtud de un rey, Los melindres de Belisa, El primero Benavides, El príncipe despeñado, La prueba de los amigos, Quien más no puede, Santiago el verde y El sembrar en buena tierra. Agradezco a Sònia Boadas y José Aragüés el envío de sus textos de La buena guarda y La hermosa Ester.

12. En cambio, el copista Ignacio Gálvez moderniza por dónde, según indica la editora de la comedia, Silvia Iriso, en el aparato crítico. 
ediciones analizadas, sin duda Lope debió de valerse en alguna que otra ocasión de estos trucos, al igual que lo hicieron muchos de sus contemporáneos ${ }^{13}$.

Así pues, se trata de un adverbio de uso muy restringido en Lope. Dejando de lado su empleo en tanto que dialectalismo o como parte de un texto prestado, con los datos a nuestra disposición podemos concluir que solo lo utilizó en oraciones interrogativas directas en función de pronombre tónico ${ }^{14}$. Sin embargo, en el proceso de transmisión de sus obras esta palabra irrumpe fácilmente en otros contextos (como adverbio relativo), según veremos a continuación.

En su edición de La amistad pagada, comedia escrita antes de 159615, Victoria Pineda utiliza como texto base un manuscrito conservado en la Biblioteca de Palacio, en el que no figura el adverbio do. Este testimonio «presenta menor número de errores y lecciones más correctas» que la versión impresa del texto ${ }^{16}$, publicada en la Parte I (1604), que ofrece diferencias notables respecto al manuscrito, incluyendo dos versos en los que sí aparece el mencionado adverbio, recogidos por Pineda en el aparato crítico. Ninguno de ellos cumple los requisitos anteriormente expuestos ${ }^{17}$ :

Éste es por quien yo resisto de Andronio y Lelio el furor, él fue mi vida y honor.

Ven, Lépido, no nos vean donde el suceso presuman. aunque no en esta ocasión

do por su causa resisto

mil lágrimas con razón

(vv. 1356-1358)

Voyme donde no nos vean por do el suceso presuman. (vv. 2227-2228)

Otro tanto ocurre en El nacimiento de Ursón y Valentín, compuesta en torno a 1589 e impresa asimismo en la Parte ${ }^{18}$. Al decir de los editores, que toman como texto base un manuscrito perteneciente a la Biblioteca de Palacio, la obra presenta

13. Un ejemplo lo tenemos en un pasaje de El bautismo del príncipe de Marruecos (v. 1751), en el que el villano Alonso echa mano de un do relativo («A fe que si hacia el lugar / do está la burra de Esteban...») y de otros «rusticismos propios de los viejos pastores del teatro» (Pontón, 2012, p. 899), o en el estribillo «Al cabo de los años mil / vuelven las aguas por do solían ir», que Lope toma de la lírica popular e inserta en Los Ponces de Barcelona (Trambaioli, 2007, p. 1147, n. 2053-2054).

14. Nótese asimismo que en los tres autógrafos aducidos se emplea para preguntar por la procedencia de algún personaje - de ahí que siempre aparezca precedido de la preposición de-, pero quizá este dato no resulte tan significativo como el anterior. A fin de cuentas, no parece difícil que un escritor que ocasionalmente se valió de una expresión como ¿De dó vienes? pudiera asimismo echar mano de otra como ¿A dó vas? o similares. En cambio, los casos que examinaremos a continuación pertenecen a tipologías gramaticales distintas.

15. Pineda, 1997, p. 1399. No sabemos qué compañía se encargó de estrenar esta comedia.

16. Pineda, 1997, p. 1403.

17. Los fragmentos a la izquierda reproducen el texto editado por Pineda, correspondiente al manuscrito conservado en la Biblioteca de Palacio. Los situados a la derecha reflejan el texto de la Parte I, tal y como se recoge en el aparato crítico. Para más detalles, véase la sección «Problemas textuales» en el prólogo a dicha edición.

18. La fecha estimada se debe a Oleza, 1986, pp. 301-303. 
una tradición textual compleja y «con toda probabilidad contaminada» ${ }^{19}$. No existen datos acerca de su estreno por parte de Gaspar de Porres, pero su ubicación en el catálogo de comedias de El peregrino en su patria invita a pensar que fue este autor el encargado de llevarla por vez primera a las tablas ${ }^{20}$. En el texto impreso en la Parte se inmiscuye de nuevo el adverbio do en función de relativo ${ }^{21}$ :
Mi vida al cuchillo ofrezco;
Mi vida al cuchillo ofrezco; vamos donde el Rey está. llévame do el Rey está. (vv. 2208-2209)
donde quisieres me lleva a do quisieres me lleva que quiero morir contigo. que quiero morir contigo. (vv. 2852-2853)

Un caso aún más significativo es el de la Comedia nueva del perseguido, terminada el 2 de noviembre de 1590 para la compañía de Alonso de Cisneros ${ }^{22}$. Esta obra fue impresa también en la Parte I, y su texto contiene dos versos con el adverbio relativo do, de nuevo en un testimonio publicado sin el control de Lope. Por el contrario, esta palabra no aparece en la copia del autógrafo llevada a cabo por Ignacio Gálvez ${ }^{23}$.

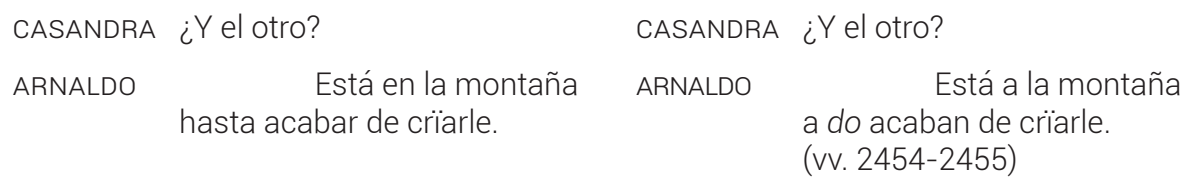

Está a la montaña a do acaban de crïarle. (vv. 2454-2455)

19. Campana y Mayol Ferrer, 1997, p. 993.

20. Fernández Rodríguez, 2014, p. 299. Los títulos del catálogo del Peregrino están agrupados en función de los autores de comedias que se encargaron de su estreno (Wilder, 1952). A su vez, las comedias incluidas en cada una de estas listas están distribuidas según un orden cronológico, más o menos preciso (Fernández Rodríguez, 2014), lo cual permite completar algunos de los repertorios descubiertos por Wilder, como en el caso que nos ocupa. Ursón y Valentín está situada entre el final del repertorio conocido de Nicolás de los Ríos y el inicio del de Gaspar de Porres: su temprana fecha de redacción, muy lejana de la del último título registrado en la lista de Ríos (El ingrato arrepentido, 1600), pero coincidente con las de los primeros de la de Porres (Las ferias de Madrid y Los celos de Rodamonte, escritas entre 1587 y 1588), sugiere que fue estrenada por este dramaturgo.

21. La columna izquierda se corresponde con el manuscrito de Palacio; la derecha, con la Parte I.

22. Véanse Wilder, 2004, p. 190, e Iriso y Morrás, 1997, p. 257.

23. Los pasajes transcritos a la izquierda pertenecen a la copia Gálvez, texto base de la edición llevada a cabo por Silvia Iriso y María Morrás (1997), de donde proceden las citas. A la derecha se reproduce el texto de la Parte I, que tomamos del aparato crítico de las editoras. Sobre la colección Gálvez, véase Iriso, 1997, así como las útiles reflexiones de Santiago Restrepo y Ramón Valdés (en prensa), a los que agradezco que me dejaran leer el excelente prólogo a su edición de El caballero del milagro. 
[...] ¿Qué combatida nave llegó al amado puerto fluctüando, que allí la esté la muerte amenazando?
[...] ¿Qué combatida nave llegó al amado puerto, do fletando, allí la esté la muerte amenazando? (vv. 2933-2935)

Lo mismo sucede en El tirano castigado, rematada el 17 de julio de 1599 y de cuyo estreno se encargó Gaspar de Porres ${ }^{24}$. En los versos 1995-1996, el manuscrito Gálvez lee «Antes por eso ofreceré la mía [la vida], / que poco importa si se pierden tantas», mientras que el texto de la Parte IV lee «Antes por eso ofreceré la mía, / que poco importa do se pierden tantas». La editora del texto, Margarita Freixas, toma como texto base el manuscrito Gálvez, pero se inclina por la lectura del impreso en estos versos. Sin embargo, no incluye esta variante de la Parte entre aquellas, explicadas en el prólogo a modo de ejemplos, preferibles a las de Gálvez, y tampoco justifica su decisión en nota; en mi opinión, no hay motivos suficientes como para desechar la lectura de Gálvez (pese a las modernizaciones en las que este incurre, muy bien descritas en el prólogo por la editora), cuyo texto, según demuestra con toda la razón Freixas, es considerablemente mejor que el de la Parte.

Por último, mencionaré el caso de La bella malmaridada, que Lope dio por finalizada el 17 de diciembre de 1596 y entregó a Nicolás de los Ríos para su representación ${ }^{25}$. La comedia se ha conservado en dos versiones distintas: en un manuscrito Gálvez, por un lado, y en la Parte II, por otro ${ }^{26}$. Según se ha encargado de advertir Enric Querol Coll, «la tradición impresa recoge y aplica la censura dada por Tomás Gracián Dantisco», además de basar su texto en «la adaptación hecha por un autor de comedias ${ }^{27}$. Pues bien, en la Parte $/ /$ el adverbio relativo do se entremete de nuevo en el texto ${ }^{28}$, mientras que no aparece en el apógrafo.

Ocupémonos ahora de las formas verbales vido y vide. Según Arjona, «Lope seldom uses the antiquated forms vido or vide for vi or vio. If he does, it is normally in peasant or vulgar speech or to obtain a chronological effect» ${ }^{29}$. Otro tanto se puede afirmar respecto al participio vido. Así sucede, por ejemplo, en La corona merecida (v. 354), el único de los veintisiete autógrafos analizados en el que aparece una de estas formas verbales: doña Sol emplea el participio vido para fingirse labradora

\footnotetext{
24. Remito a Ferrer Valls, 2008, y a Fernández Rodríguez, 2014, p. 295.

25. Véase Ferrer Valls, 2008, y Fernández Rodríguez, 2014, p. 290.

26. Tal y como explica el editor moderno de la comedia, que ha transcrito los dos testimonios por separado, «las numerosas variantes textuales [...] permiten hablar de dos versiones del texto» (Querol Coll, 1998, p. 1185)

27. Querol Coll, 1998, p. 1185.

28. Se trata del verso 754, que puede consultarse en la versión impresa del texto, editada por Querol Coll (1998, pp. 1297-1390). Por otra parte, en los vv. 129, 2696 y 2728 de la Parte II encontramos un do en función de adverbio tónico en oraciones interrogativas (si bien ninguno aparece introducido por la preposición de, al contrario que en los autógrafos): son, claro está, demasiados casos para Lope. 29. Arjona, 1960, p. 322.
} 
(«Ni los he vido en jamás»), simulando así «una forma de hablar rústica», según anota oportunamente Fernando Rodríguez-Gallego ${ }^{30}$.

Una búsqueda en la base de datos TESO de las palabras vido y vide en Lope arroja diferentes resultados, los más pertenecientes en efecto al habla villanesca y rústica ${ }^{31}$. En algunos casos se emplean (junto con otros fenómenos, tales como la conservación de la f- inicial latina) para obtener ese «chronological effect» del que hablaba Arjona (en Las famosas asturianas, por ejemplo), o bien para caracterizar el habla dialectal de algún personaje; en otros, forman parte de romances o villancicos, que, debido a su antigüedad, presentan usos arcaicos como vido o vide. Tal es el caso de los versos, pertenecientes al romance «Por los campos de Alventosa» ${ }^{32}$, que figuran en El casamiento en la muerte (vv. 1960-2004), en los que la forma vido aparece hasta en tres ocasiones.

Las únicas comedias en las que el TESO permite documentar la presencia de las voces vido y vide sin ninguna connotación rústica, cronológica o dialectal son El nacimiento de Ursón y Valentín, La bella malmaridada, La noche toledana y Los donaires de Matico ${ }^{33}$. En las tres primeras, solo aparecen en los impresos (Parte I, II y III respectivamente), mientras que están ausentes en la tradición manuscrita, más cercana al texto original según los editores ${ }^{34}$. De nuevo, una transmisión textual accidentada propicia la aparición de expresiones en principio ajenas o muy excepcionales en Lope. Por lo que respecta a Los donaires de Matico, la Parte I, en la que puede leerse la palabra vido, es el testimonio empleado como texto base por su editor, Marco Presotto. El término aparece en el v. 988 («que le vido correr, y no fue acaso»), verso que en el manuscrito de Palacio en el que también se ha conservado la obra es completamente distinto («que le trataron del estraño caso») ${ }^{35}$ :

RAMIRO Luego desa manera la Condesa tendrale amor.

30. Rodríguez-Gallego, 2015, p. 650. El aparato crítico de esta edición nos advierte que el texto de la Parte XIV, en la que fue impresa la comedia, moderniza el verso, sustituyendo vido por visto, lección que acogieron Juan Eugenio Hartzenbusch y Marcelino Menéndez Pelayo; se trata de una prueba más de la necesidad de valerse siempre de autógrafos o ediciones críticas fiables en los estudios de atribuciones literarias.

31. Una consulta en el Corde y en Fernández Gómez, 1971, no aporta más ejemplos.

32. Según explica Luigi Giuliani, 1997, p. 1261.

33. La comedia El más galán portugués, duque de Berganza contiene los versos siguientes: «Pero como vido el paje / entra con lengua atrevida»; en nota a su edición, Carlos Mota (2009) advierte con toda la razón que, en realidad, la lectura correcta es «Pero comovido ('conmovido') el paje, / entra con lengua atrevida» (vv. 2216-2217).

34. Véanse los versos 456, 459, 1453 y 3137 de El nacimiento de Ursón y Valentín. En cuanto a La bella malmaridada, el verbo vide figura en el verso 2288 de la versión impresa, mientras que no aparece en la copia llevada a cabo por Ignacio Gálvez (véase la edición de Querol Coll, 1998). Por último, en los versos 1902 y 2078 de La noche toledana la forma vide se encuentra en el texto impreso en la Parte III, pero no en el manuscrito que, «dada su superioridad sobre el resto de los testimonios», sirve de texto base para la edición de Sánchez Aguilar (2002, p. 72). Esta obra fue escrita en 1605 para la compañía de Nicolás de los Ríos (Sánchez Aguilar, 2002, p. 63).

35. Transcribo en primer lugar el texto de la Parte l; a continuación, el del manuscrito de Palacio. 


\begin{tabular}{|c|c|}
\hline RIQUELMO & $\begin{array}{l}\text { ¿Quién dices? Rosimur } \\
\text { ya por los bellos ojos lo confiesa } \\
\text { tenerle amor de voluntad profunda, } \\
\text { y desto sé que al Conde no le pesa; } \\
\text { porque la vez primera y la segunda } \\
\text { que le vido correr, y no fue acaso, } \\
\text { quedáronsele junto lengua y paso. }\end{array}$ \\
\hline RAMIRO & $\begin{array}{l}\text { Luego desa manera la Condesa } \\
\text { tendrale amor. }\end{array}$ \\
\hline RIQUELMO & $\begin{array}{l}\text { ¿Qué dices? Rosimunda } \\
\text { ya por los bellos ojos le confiesa } \\
\text { tener amor y voluntad profunda, } \\
\text { y desto sé que al Conde no le pesa; } \\
\text { porque la vez primera y la segunda } \\
\text { que le trataron del estraño caso } \\
\text { cerráronsele juntos lengua y paso. } \\
\text { (vv. 982-989) }\end{array}$ \\
\hline
\end{tabular}

El texto impreso en la Parte I presenta asimismo dos versos en los que aparece el adverbio do: «siguiéndote por do vas» (v. 760), verso absolutamente distinto en el manuscrito («que no se cansan jamás»), y «y hagámonos bien fuertes do aquel monte» (v. 2098), que en el manuscrito se corresponde con «llegarémonos juntos [a] aquel monte». Ninguno de ellos, como vemos, desempeña la función de adverbio tónico en una oración interrogativa directa.

Si todas estas lecciones de la Parte I se corresponden con el texto originalmente escrito por Lope, la presencia de vido y do podría explicarse quizá por la muy temprana fecha de redacción de la comedia, escrita como muy tarde en $1589^{36}$. No se olvide que entre los cuarenta y cuatro autógrafos lopescos conservados, solo el primer acto de El favor agradecido (1593) es anterior a 1600, por lo que conviene extremar la cautela en todo cuanto atañe a la producción del jovencísimo Lope, el de los años ochenta y, en menor medida, primeros noventa. Aunque es probable que sus usos y costumbres al respecto fueran consistentes a lo largo de su vida, no cabe cerrar del todo la puerta a posibles variaciones en sus obras más tempranas ${ }^{37}$.

Con todo, tal y como explica Marco Presotto, la tradición textual de esta comedia es muy compleja, pues si bien los impresos han transmitido «un texto más completo y correcto de Los donaires de Matico respecto a la copia manuscrita»,

36. Oleza, 1986, pp. 301-303, Reyes Peña, 1996, pp. 198-199, y Fernández Rodríguez, 2014, pp. 291-292. 37. Más adelante veremos que en algunas poesías de Lope escritas en los años ochenta y noventa aparece el adverbio do en contextos contrarios al usus scribendi autorizado por los autógrafos dramáticos (pero también tras ellas podrían ocultarse intervenciones ajenas). Por otro lado, no se me escapa que alguna de las obras consideradas anteriormente pertenece asimismo a la primera etapa del dramaturgo; en todas ellas, no obstante, la presencia de las voces estudiadas se suma a otros indicios de deturpación textual debidamente puntualizados por los respectivos editores. 
esta «presenta una gran cantidad de lecciones singulares: algunas son meliores, otras pueden remontarse a la intervención de algún autor de comedias, pero en general son difícilmente explicables y hay quizás que suponer la presencia de variantes de autor ${ }^{38}$. Así pues, se trata de un caso dudoso: las palabras vido y do podrían deberse a la intervención de una compañía - quizá la de Ríos, que se encargó de estrenarla-39, pero también a la pluma de un jovencísimo Lope.

Hay un breve pasaje de La viuda valenciana que puede servir para ejemplificar los problemas filológicos con los que se enfrenta el autor de una edición crítica en relación con el asunto que tenemos entre manos. Mientras que la Parte XIV, texto base empleado en las dos ediciones críticas modernas, carece de las formas do y vide, ambas aparecen en cambio en un manuscrito de compañía en el que se ha transmitido la pieza ${ }^{40}$ :

Dos ventanas más abajo vivía un buen zapatero, donde yo con gran cuidado puse los ojos, por ver la casa en que viven tantos. Y vi en un balcón un bulto, la mitad del cuerpo blanco.
Dos ventanas más abajo vivía un buen zapatero, donde yo con gran cuidado puse los ojos, por ver la casa do viven tantos. Vide en un balcón un bulto, la mitad del cuerpo blanco. (vv. 531-537)

El texto del manuscrito es considerablemente peor que el de la Parte, pero aquel, sin embargo, parece remontarse a una versión más antigua de la comedia, mientras que todo indica que Lope retocó la pieza para su publicación en la Parte XIV ${ }^{47}$. Así pues, ¿las palabras do y vide se deben a la intromisión de una compañía teatral, y no a la pluma del poeta, o, por el contrario, reflejan una primera redacción de la comedia? Aun inclinándonos por esta segunda posibilidad, lo cierto es que el texto de la Parte, que fue revisado por Lope, no incluye esas dos palabras. Podríamos pensar, pues, que decidió corregirlas, amoldándolo a sus hábitos de entonces; en ese caso, deberíamos también aceptar la lectura de la Parte XIV, en tanto que esta reflejaría la última voluntad del poeta. Pero, ¿y si el texto con el que se hizo Lope para publicar La viuda valenciana incorporaba ya las variantes $Y$ vi y en que? De ser así, sería imposible que el Fénix restaurara las lecciones originarias. Podríamos zanjar la cuestión concluyendo que se trata de variantes adiáforas, y que por consiguiente debemos decantarnos por el texto de la Parte. Sin duda parece lo más razonable. Pero es que, no lo olvidemos, esos dos versos contradicen todo cuanto sabemos acerca del usus scribendi lopesco por lo que atañe a las formas do y vide. Por otra parte, la fecha de composición de la obra (1599-1600) no parece lo suficientemente

38. Son palabras de Marco Presotto, 1997, p. 124.

39. Reyes Peña, 1996.

40. La columna de la izquierda se corresponde con el texto de la Parte XIV; la de la derecha, con el manuscrito.

41. Ferrer Valls, 2001, pp. 62-69, y Ramos, 2015, pp. 843-850. 
remota como para concederle tanto crédito ${ }^{42}$. Así pues, todo apunta a que la lección del manuscrito se debe a una mano ajena al poeta ${ }^{43}$, probablemente a la intervención de una compañía dramática. Quizá la de Gaspar de Porres, que se encargó de estrenarla, o la de Hernán Sánchez de Vargas, al que perteneció dicho manuscrito ${ }^{44}$.

Como curiosidad, pero también a modo de advertencia, recordaré que incluso en ediciones realizadas en tiempos en que las palabras objeto de examen estaban ya desterradas de la lengua, es posible no obstante que una voz como do se inmiscuya en un texto de Lope. Y en uno bien conocido, por cierto. Sin apearnos de La viuda valenciana, el aparato crítico preparado por Rafael Ramos nos informa de que Hartzenbusch y Menéndez Pelayo decidieron reemplazar el habitual adverbio donde por su correspondiente forma antigua en la siguiente quintilla: «Una medalla hacer quiero, / aunque pobre caballero, / de plata y de mil tesoros, / donde estén como el cinco oros / la vïuda y su escudero» (vv. 2352-2356). Hartzenbusch prefirió la forma do, acuciado quizá por la sinalefa entre cinco y oros, sin duda muy forzada en la actualidad, pero posible en la ortología lopesca ${ }^{45}$. Si estos cambios se producen en ediciones más o menos cuidadas y tan lejanas en el tiempo respecto a los escritos originales, ¿qué no ocurriría en el Siglo de Oro con unos textos efímeros y volátiles, destinados a ser una pieza más en el vertiginoso engranaje del negocio teatral, y no un objeto poco menos que sacrosanto para filólogos de buena fe?

Cabe preguntarse a continuación qué ocurre en los otros géneros cultivados por Lope respecto a los tres vocablos estudiados. Aunque las conclusiones que puedo esbozar aquí no dejan de ser provisionales, parece que su uso es también muy restringido tanto en la prosa como en la poesía ${ }^{46}$. El verbo vido figura en el romance morisco «Gallardo pasea Zaide» (vv. 5 y 21), de dudosa autoría ${ }^{47}$. Si se debe a Lope, su presunta y temprana fecha de redacción (años ochenta) podría explicar la presencia de esta forma verbal. En cuanto a la palabra vide, únicamente la he localizado en un verso de la Jerusalén conquistada, publicada en $1609^{48}$. Por

42. Para su fecha de redacción, véanse Ferrer Valls, 2001, p. 26, y Ramos, 2015, pp. 833-834. Varios autógrafos están fechados en esos mismos años: El primero Benavides (1600), El cuerdo loco (1602), El príncipe despeñado (1602), La corona merecida (1603) y El cordobés valeroso Pedro Carbonero (1603). 43. Rafael Ramos (2015, p. 847) incluye el verso 535 entre aquellos de la versión impresa cuya lección «parece mucho mejor» que la manuscrita.

44. Ferrer Valls, 2003

45. Poesse (1949, p. 55) recoge la forma como hoy, también con sinalefa y en posición de acento rítmico. Por su parte, Menéndez Pelayo no solo optó por la forma do, sino que introdujo además la preposición de entre cinco y oros. El verso de la Parte, sin embargo, no presenta problemas métricos, pues el sintagma cinco oros era corriente en aquella época, según ilustra en nota Rafael Ramos.

46. No me ha sido posible analizar su presencia en los autos sacramentales del Fénix, aunque lo más lógico es que no haya diferencias notables. Sobre los autos sacramentales lopescos, remito a Nogués, 2011, e Izquierdo Domingo, 2013 y 2014.

47. Antonio Sánchez Jiménez (2015) no lo incluye entre los romances juveniles atribuibles con garantías a Lope. Puede leerse el texto en la edición de Antonio Carreño, 1998, p. 8.

48. Véase la edición de Joaquín de Entrambasaguas, 1951, p. 72, v. 25. 
lo que respecta al adverbio do, solo he podido hallarlo en cinco romances juveniles, escritos en los ochenta y noventa. ${ }^{49}$

¿Y qué hay de otros dramaturgos? Como es natural, la lengua de cada uno de nuestros poetas tiene sus particularidades, por lo que no conviene generalizar en exceso. Tras realizar varias consultas en el TESO, y cotejar los resultados con las ediciones correspondientes, se diría que entre los incluidos en dicha base de datos solo Lope de Rueda, Juan de la Cueva y Guillén de Castro emplearon con cierta asiduidad las formas verbales vide y vido ${ }^{50}$. En cuanto al uso del adverbio do, algunos ingenios, como Tirso y Calderón, parecen asemejarse mucho a Lope $e^{51}$. Por lo visto, solo Lope de Rueda, Juan de la Cueva, Miguel de Cervantes y Guillén de Castro me limito siempre al grupo de dramaturgos recogidos en el TESO- se valieron de él con harta frecuencia. En el caso de Cervantes, por ejemplo, no hay comedia suya que no contenga este adverbio -en algunas se cuentan por docenas- en contextos de lo más variopinto ${ }^{52}$. Estas primeras impresiones, por un lado, nos invitan a ser cautos, y nos previenen acerca de la necesidad de examinar cada caso por separado; por otro, nos animan a sugerir una hipótesis: en los primeros años de la Comedia Nueva, estas palabras siguen presentes en la lengua literaria de algunos escritores y directores de compañía (entre estos últimos cabría incluir con poco margen de error a Porres y Ríos), razón por la que a veces irrumpen en textos que carecían de ellas (como les ocurrió a los de Lope, según hemos visto). Con el paso del siglo, sin embargo, irán desapareciendo de las plumas de los poetas, y también de los tablados (sobre todo en el caso de los verbos vide y vido, más arcaicos).

Todos los casos aducidos en este artículo pertenecen a comedias compuestas entre 1589 y 1600 -salvo La noche toledana, escrita en 1605-, por lo que las manipulaciones textuales expuestas se llevaron a cabo en los años 90 o, a lo sumo, en los primeros del nuevo siglo, antes de su publicación en la Parte I en 1604 (Los donaires de Matico, Comedia nueva del perseguido, El nacimiento de Ursón y Valentín, reyes de Francia y La amistad pagada), la Parte II en 1609 (La bella malmaridada), la Parte III en 1612 (La noche toledana), la Parte IV en 1614 (El tirano castigado) y, finalmente, la Parte XIV en 1620 (La viuda valenciana). Por esos años, los vocablos analizados aún no debían de sentirse extraños para su uso en las tablas. En este sentido, es muy significativo que todas las comedias de la Parte I, salvo La escolástica celosa, presenten versos con el adverbio do en condiciones en principio con-

49. Se trata de los romances «De una recia calentura» (v. 26), «El famoso ganadero» (v. 76), «No tengas, dulce Belisa» (v. 81), «Mil años ha que no canto» (v. 63) y «Hermosa Lucinda mía» (v. 16), escrito probablemente en 1599-1604 (Sánchez Jiménez, 2015, p. 329). Todos estos poemas pueden leerse en la excelente edición de Antonio Sánchez Jiménez, 2015

50. El TESO está formado por más de 800 comedias pertenecientes a los siguientes dramaturgos: Pedro Calderón de la Barca, Guillén de Castro, Miguel de Cervantes, Juan de la Cueva, Juan Bautista Diamante, Juan de Matos Fragoso, Agustín Moreto, Juan Pérez de Montalbán, Luis Quiñones de Benavente, Francisco de Rojas Zorrilla, Lope de Rueda, Juan Ruiz de Alarcón, Antonio de Solís, Tirso de Molina, Lope de Vega y Antonio Zamora.

51. En ambos es común el uso del adverbio do para caracterizar el habla de villanos y pastores.

52. Puede leerse su teatro en la reciente edición al cuidado de Luis Gómez Canseco, 2015. 
trarias a los usos del Fénix ${ }^{53}$. Es un hecho que no tiene parangón en ninguna de las otras Partes publicadas a su nombre, y un indicio más del severo deterioro textual de este testimonio, que lamentó amargamente el propio Lope («a seis renglones míos ciento ajenos...»). Pese a la temprana fecha de composición de las comedias compiladas, lo más probable es que tras la mayoría de estos casos se escondan intervenciones de manos ajenas. El caso más flagrante es el de la Comedia de Bamba, escrita antes de Cuaresma de 1597 y estrenada por Gaspar de Porres ${ }^{54}$, la cual registra un total de doce usos no lopescos del adverbio do. Tan desmedida cifra da buena cuenta, por sí sola, del mal estado del texto ${ }^{55}$, y podría añadirse a los demás indicios de deturpación detectados por el editor. Y otro tanto se puede afirmar respecto a El nacimiento de Ursón y Valentín, que contiene dos ejemplos de un do relativo y cuatro versos con la palabra vide en contextos ajenos a Lope.

Las otras Partes con más usos no autorizados del adverbio do son la II y la IV, circunstancia que avala la hipótesis defendida en torno a la cronología de dicha palabra ${ }^{56}$. Ambas, sin embargo, presentan un número de casos francamente lejano respecto al de su predecesora.

La inusitada concentración del adverbio relativo do en la primera gran recopilación de comedias lopescas podría, quizá, ser un indicio de que todos los manuscritos reunidos por Bernardo Grassa y entregados al impresor Angelo Tavanno tenían una procedencia común ${ }^{57}$. Sabemos que estuvieron en posesión de distintos autores de comedias (Porres, Ríos, Cisneros...), y nada impide que, entre sus numerosas intervenciones, todos ellos usaran esa misma forma lingüística al adaptar los autógrafos lopescos. Pero, aun así, la sospechosa reiteración en once de las doce comedias compiladas invita a pensar en una mano presente en esos textos durante la transmisión escrita previa a la impresión.

53. Además de las comedias examinadas, véanse El casamiento en la muerte (vv. 1387 y 1860), El cerco de Santa Fe (vv. 466, 707 y 1731), la Comedia de Bamba (vv. 222, 459, 506, 772, 805, 957, 1125, 1186, 1614, 1630, 2403 y 2485), El hijo de Reduán (v. 2872), El molino (v. 554), El testimonio vengado (vv. 280, 608 y 2131) y La traición bien acertada (vv. 687, 1033, 1161, 2156 y 2315). No incluyo en este recuento el v. 2390 de El hijo de Reduán («Helo dó viene el fuerte granadino»), que no es sino una recreación del comienzo de varios romances viejos («Helo, helo por dó viene / el moro por la calzada...»), imitado o parodiado por Lope en otras comedias (por ejemplo, en El bobo del colegio, vv. 3159-3160).

54. Wilder, 2004, p. 192.

55. «La Comedia de Bamba presenta un texto muy deturpado, con algunas lagunas y multitud de errores» (Roas, 1997, p. 566).

56. En la Parte Il aparece en cinco ocasiones (sin contar los casos ya aducidos de La bella malmaridada): Las ferias de Madrid (v. 100), El mayorazgo dudoso (v. 418), La ocasión perdida (v. 2818), El padrino desposado (v. 504) y La quinta de Florencia (v. 558). En cuanto a la Parte IV, figura en El amigo por fuerza (v. 315) y en El nuevo mundo descubierto por Cristóbal Colón (v. 1453), ejemplos que se suman a los versos ya analizados de El tirano castigado. Se trata de comedias escritas en torno a 1599-1603 -salvo Las ferias de Madrid, fechable en 1587 (McGrady, 2007, p. 7)-, y representadas por diferentes autores, tales como Porres, Ríos o Baltasar de Pinedo. No incluyo entre los casos de la Parte // un verso de La fuerza lastimosa en el que las primeras ediciones, por trivialización, leen «do sale», cuando la lectura correcta es a todas luces «dosel», según enmiendan con acierto algunos testimonios: «Su merced sobre esta piedra / se siente mientras venimos. / Será dosel esa yedra / con sus hojas y racimos» (vv. 332-335). 57. Debo esta observación a Gonzalo Pontón, que tuvo la amabilidad de leer estas páginas. 
En otro orden de cosas, los ejemplos aducidos bastan para dar cuenta de los múltiples cambios que los textos dramáticos padecen en el proceso de transmisión, los cuales nos previenen acerca de la fiabilidad que hay que otorgar al estudio del vocabulario en obras que presentan un grado más o menos avanzado de deturpación textual. Como hemos tenido ocasión de observar, una transmisión accidentada puede provocar la irrupción, en varias ocasiones y en un mismo texto, de voces extrañas al usus scribendi de un poeta; con todo, su presencia no debería ser nunca una prueba irrefutable contra la autoría originaria o remota de una obra, pero sí un indicio relevante ${ }^{58}$. La prudencia con que deberíamos proceder en este terreno es extensible al análisis de la ortología y de la rima, así como al estudio de fenómenos como la hipermetría y la hipometría. Difícilmente uno solo de estos rasgos bastará para zanjar una atribución literaria. Bastante más seguros son los datos extraídos de la versificación estrófica, a la que afectan en menor medida los avatares de la transmisión teatral, salvo en el caso de una profunda refundición. Pero, sobre todo, es la suma de distintos indicios lo que aporta validez a un estudio de estas características.

Por otra parte, la presencia de rasgos contrarios al supuesto o seguro autor de una obra es un dato muy útil para calibrar el desgaste textual de cualquier testimonio, por lo que su estudio constituye una herramienta eficacísima a la hora de realizar una edición crítica de una comedia del Siglo de Oro.

En el caso particular que nos ocupa, los datos analizados, extraídos de veintisiete ediciones críticas basadas en sendos autógrafos lopescos, confirman la rareza de las palabras do, vide y vido en Lope. El uso de do se restringe a su función como adverbio tónico en oraciones interrogativas directas (salvo en el caso puntual de préstamos textuales o de imitación de algún dialecto particular), mientras que vide y vido se limitan a colorear el habla antigua o rústica de algún personaje. La presencia, en otras condiciones, de cualquiera de estos términos en un texto dramático atribuido a Lope debe ponernos sobre aviso: probablemente nos las habremos con uno de los incontables cambios ajenos al poeta. De ser así, deberemos sopesar las alternativas textuales pertinentes, ofrecidas o no por los demás testimonios de la obra, aun cuando en muchos casos sea imposible reconstruir el texto original ${ }^{59}$. Algo más dudosas, quizá, pero igualmente sospechosas, son las comedias de fecha muy temprana, como Los donaires de Matico (1589), pues no contamos con manuscritos autógrafos de esa época que avalen los datos disponibles. Incluso cuando manejemos textos escritos en fechas más tardías, las decisiones al respecto no estarán nunca exentas de cierto riesgo: al fin y al cabo, nuestro trabajo se basa en una muestra representativa del teatro lopesco, pero ni mucho menos -es

58. Ahora bien, ¿hasta qué punto es operativa la noción de autoría? Recordemos el lamento de Lope: «Viendo imprimir cada día mis comedias, de suerte que era imposible llamarlas mías». ¿Qué grado de deturpación, manipulación o refundición soporta un texto antes de que podamos, o debamos, arrebatarle la autoría originaria? Son preguntas complejas, que por ahora solo nos vemos con ánimo de plantear. 59. Abordar las particularidades de la lengua de los dramaturgos del Siglo de Oro es tarea ímproba, pero necesaria, para leer y entender mejor a nuestros clásicos. A esta labor se han dedicado admirables y valiosísimos esfuerzos, en fechas remotas y recientes, por parte de muchos estudiosos, a los que no me he podido remitir por falta de espacio. 
imposible- exhaustiva ${ }^{60}$. Se trata, en definitiva, de ir conociendo cada vez mejor la lengua de nuestros poetas, a fin de ir esclareciendo poco a poco los intrincados misterios que aún nos deparan.

\section{BIBLIOGRAFÍA}

Arjona, José Homero, «Ten Plays Attributed to Lope de Vega», Hispanic Review, 28, 1960, pp. 319-340.

Aubrun, Charles V., La comedia española: 1600-1680, Madrid, Taurus, 1968.

Blecua, Alberto, «Sobre la (no) puntuación en los textos dramáticos del Siglo de Oro», en En buena compañía. Estudios en honor de Luciano García Lorenzo, coord. Joaquín Álvarez Barrientos, Óscar Cornago Bernal, Abraham Madroñal Durán y Carmen Menéndez-Onrubia, Madrid, CSIC, 2009, pp. 79-101.

Campana, Patrizia, y Juan-Ramón Mayol Ferrer (ed.), Lope de Vega, El nacimiento de Ursón y Valentín, reyes de Francia, en Comedias de Lope de Vega. Parte I, Lleida, Milenio/Universitat Autònoma de Barcelona, 1997, II, pp. 981-1148.

Carreño, Antonio (ed.), Lope de Vega, Rimas humanas y otros versos, Barcelona, Crítica, 1998.

Corde: Corpus diacrónico del español, Real Academia Española. Disponible en línea: $<$ http://corpus.rae.es/cordenet.html> [19/03/2016].

Dixon, Victor, «La intervención de Lope en la publicación de sus comedias», Anuario Lope de Vega, 2, 1996, pp. 45-63.

Entrambasaguas, Joaquín de (ed.), Lope de Vega, Jersusalén conquistada, Madrid, CSIC, 1951, II.

Fernández Gómez, Carlos, Vocabulario completo de Lope de Vega, Madrid, Real Academia Española, 1971.

Fernández Rodríguez, Daniel, «Nuevos datos acerca de los repertorios teatrales en el primer catálogo de El peregrino en su patria», Studia Aurea, 8, 2014, pp. 277-314.

Ferrer Valls, Teresa (ed.), Lope de Vega, La viuda valenciana, Madrid, Castalia, 2001.

Ferrer Valls, Teresa, «La vigencia en cartel de una comedia: La viuda valenciana, del repertorio de Gaspar de Porres al de Hernán Sánchez de Vargas», en Homenaje a Luis Quirante, coord. Rafael Beltrán Llavador, Valencia, Universitat de València, 2003, I, pp. 175-190.

60. En este sentido, el caso más interesante de todos los registrados en el TESO pertenece a El amigo por fuerza, comedia escrita en 1599, estrenada por Porres y publicada en 1614 en la Parte IV (Pontón y Laplana, 2002, p. 933). En el v. 315, tanto la Parte IV como el manuscrito Gálvez registran un do en función de adverbio relativo («por do subió la maldad»), una excepción que confirma la norma pero que, a la vez, invita a ser cautos y contemplar siempre todas las posibilidades. 
Ferrer Valls, Teresa (dir.), Diccionario biográfico de actores del teatro clásico español (DICAT), Kassel, Reichenberger, 2008 [recurso electrónico], [18/03/2016].

Fichter, William L., «Orthoëpy as an aid for establishing a canon of Lope de Vega's authentic plays», en Estudios hispánicos. Homenaje a Archer M. Huntington, Wellesley, Spanish Department/Wellesley College, 1952, pp. 143-153.

Freixas, Margarita (ed.), Lope de Vega, El tirano castigado, en Comedias de Lope de Vega. Parte IV, coords. Luigi Giuliani y Ramón Valdés, Lleida, Milenio/Universitat Autònoma de Barcelona, 2002, III, pp. 1493-1638.

García-Reidy, Alejandro, «¿Competencia o colaboración? Memoriones, copistas y actores en un manuscrito de El príncipe perfecto (primera parte)», en El patrimonio del teatro clásico español: actualidad y perspectivas. Homenaje a Francisco Ruiz Ramón, ed. Germán Vega, Héctor Urzáiz y Pedro Conde, Valladolid/Olmedo, Universidad de Valladolid/Ayuntamiento de Olmedo, 2015, pp. 381-389.

Giuliani, Luigi (ed.), Lope de Vega, El casamiento en la muerte, en Comedias de Lope de Vega. Parte I, Lleida, Milenio/Universitat Autònoma de Barcelona, 1997, II, pp. 1149-1276.

Gómez Canseco, Luis (coord.), Miguel de Cervantes, Comedias y tragedias, Madrid, Real Academia Española, 2015.

Iriso Ariz, Silvia, «Estudio de la colección Gálvez: fiabilidad y sentido de los apógrafos de Lope de Vega», Anuario Lope de Vega, 3, 1997, pp. 99-143.

Iriso Ariz, Silvia (ed.), Lope de Vega, El primero Benavides, en Comedias de Lope de Vega. Parte II, coord. Silvia Iriso, Lleida, Milenio/Universitat Autònoma de Barcelona, 1998, II, pp. 839-1022.

Iriso, Silvia y María Morrás (ed.), Lope de Vega, Comedia nueva del perseguido, en Comedias de Lope de Vega. Parte I, Lleida, Milenio/Universitat Autònoma de Barcelona, 1997, I, pp. 255-458.

Izquierdo Domingo, Amparo, Los autos sacramentales de Lope de Vega: clasificación e interpretación, Vigo, Academia del Hispanismo, 2013.

Izquierdo Domingo, Amparo, Los autos sacramentales de Lope de Vega: funciones dramáticas, New York, Instituto de Estudios Auriseculares, 2014.

McGrady, Donald (ed.), Lope de Vega, Las ferias de Madrid, Newark, Juan de la Cuesta, 2007.

Mota, Carlos (ed.), Lope de Vega, El más galán portugués, Duque de Berganza, en Comedias de Lope de Vega. Parte VIII, coord. Rafael Ramos, Lleida, Milenio/ Universitat Autònoma de Barcelona, 2009, I, pp. 429-568.

Nogués Bruno, María, Clasificación de los autos sacramentales de Lope de Vega, Bellaterra, Universitat Autònoma de Barcelona, 2011. 
Oleza, Joan, «La propuesta teatral del primer Lope de Vega», en Teatro y prácticas escénicas, II. La comedia, ed. Joan Oleza, London, Tamesis Books, 1986, pp. 251-308.

Pineda, Victoria (ed.), Lope de Vega, La amistad pagada, en Comedias de Lope de Vega. Parte I, Lleida, Milenio/Universitat Autònoma de Barcelona, 1997, III, pp. 1397-1545.

Poesse, Walter, The Internal Line-Structure of Thirty Autograph Plays of Lope de Vega, Bloomington, Indiana University, 1949.

Pontón, Gonzalo (ed.), Lope de Vega, El hijo de Reduán, en Comedias de Lope de Vega. Parte I, Lleida, Milenio/Universitat Autònoma de Barcelona, 1997, II, pp. 817-980.

Pontón, Gonzalo (ed.), Lope de Vega, El bautismo del príncipe de Marruecos, en Comedias de Lope de Vega. Parte XI, coords. Laura Fernández y Gonzalo Pontón, Madrid, Gredos, 2012, II, pp. 791-960.

Pontón, Gonzalo, y José Enrique Laplana (eds.), Lope de Vega, El amigo por fuerza, en Comedias de Lope de Vega. Parte IV, coord. Luigi Giuliani y Ramón Valdés, Lleida, Milenio/Universitat Autònoma de Barcelona, 2002, II, pp. 923-1080.

Presotto, Marco (ed.), Lope de Vega, Los donaires de Matico, en Comedias de Lope de Vega. Parte I, Lleida, Milenio/Universitat Autònoma de Barcelona, 1997, I, pp. 115-254.

Presotto, Marco, «La Novena parte: historia editorial», en Comedias de Lope de Vega. Parte IX, coord. Marco Presotto, Lleida, Milenio/Universitat Autònoma de Barcelona, 2007, I, pp. 7-38.

Profeti, Maria Grazia, «Comedias representadas/textos literarios: Ios problemas ecdóticos», en Lope de Vega, Los donaires de Matico, ed. Marco Presotto, Kassel, Reichenberger, 1994, pp. IX-XVII.

Querol Coll, Enric (ed.), Lope de Vega, La bella malmaridada, en Comedias de Lope de Vega. Parte II, coord. Silvia Iriso, Lleida, Milenio/Universitat Autònoma de Barcelona, 1998, II, pp. 1175-1389.

Ramos, Rafael (ed.), Lope de Vega, La viuda valenciana, en Comedias de Lope de Vega. Parte XIV, coord. J. Enrique López Martínez, Madrid, Gredos, 2015, I, pp. 831-999.

Restrepo, Santiago, y Ramón Valdés (ed.), Lope de Vega, El caballero del milagro, en Comedias de Lope de Vega. Parte XV, coord. Luis Sánchez Laílla, Madrid, Gredos [en prensa].

Reyes Peña, Mercedes de los, «Una nota sobre el terminus ad quem de Los donaires de Matico, de Lope de Vega, y su inclusión en el repertorio de Nicolás de los Ríos», Anuario Lope de Vega, 2, 1996, pp. 197-211. 
Roas, David (ed.), Lope de Vega, Comedia de Bamba, en Comedias de Lope de Vega. Parte I, Lleida, Milenio/Universitat Autònoma de Barcelona, 1997, I, pp. 559685.

Rodríguez-Gallego, Fernando (ed.), Lope de Vega, La corona merecida, en Comedias de Lope de Vega. Parte XIV, coord. J. Enrique López Martínez, Madrid, Gredos, 2015, I, pp. 583-829.

Ruano de la Haza, José M., «An Early Rehash of Lope's Peribáñez», Bulletin of the Comediantes, 35, 1983, pp. 5-29.

Sánchez Aguilar, Agustín (ed.), Lope de Vega, La noche toledana, en Comedias de Lope de Vega. Parte III, coord. Luigi Giuliani, Lleida, Milenio/Universitat Autònoma de Barcelona, 2002, pp. 57-251.

Sánchez Jiménez, Antonio (ed.), Lope de Vega, Romances de juventud, Madrid, Cátedra, 2015.

TESO: Teatro Español del Siglo de Oro, versión 3.00 [Recurso electrónico], Madrid, Chadwyck-Healey España, 1997-1998.

Trambaioli, Marcella (ed.), Lope de Vega, Los Ponces de Barcelona, en Comedias de Lope de Vega. Parte IX, coord. Marco Presotto, Lleida, Milenio/Universitat Autònoma de Barcelona, 2007, III, pp. 1053-1154.

Vega, Lope de, Carlos V en Francia, ed. Arnold G. Reichenberger, Philadelphia, University of Pennsylvania Press, 1962.

Vega, Lope de, Comedia de Bamba, ed. David Roas, en Comedias de Lope de Vega. Parte I, Lleida, Milenio/Universitat Autònoma de Barcelona, 1997, I, pp. 559685.

Vega, Lope de, Comedia nueva del perseguido, eds. Silvia Iriso y María Morrás, en Comedias de Lope de Vega. Parte I, Lleida, Milenio/Universitat Autònoma de Barcelona, 1997, I, pp. 255-458.

Vega, Lope de, ¿De cuándo acá nos vino?, ed. Delia Gavela García, Kassel, Reichenberger, 2008.

Vega, Lope de, Del monte sale quien el monte quema, ed. Ana María Porteiro Chouciño, Santiago de Compostela, Universidade de Santiago de Compostela, 2007.

Vega, Lope de, El amigo por fuerza, eds. Gonzalo Pontón y José Enrique Laplana, en Comedias de Lope de Vega. Parte IV, coords. Luigi Giuliani y Ramón Valdés, Lleida, Milenio/Universitat Autònoma de Barcelona, 2002, II, pp. 923-1080.

Vega, Lope de, El bautismo del príncipe de Marruecos, ed. Gonzalo Pontón, en Lope de Vega, Comedias de Lope de Vega. Parte XI, coords. Laura Fernández y Gonzalo Pontón, Madrid, Gredos, 2012, II, pp. 791-960.

Vega, Lope de, El bobo del colegio, ed. Jorge Checa, en Comedias de Lope de Vega. Parte XIV, coord. J. Enrique López Martínez, Madrid, Gredos, 2015, II, pp. 553724. 
Vega, Lope de, El caballero del sacramento, ed. Donald McGrady, Newark, Juan de la Cuesta, 2007.

Vega, Lope de, El cardenal de Belén, ed. Natalia Fernández Rodríguez, en Comedias de Lope de Vega. Parte XIII, coord. N. Fernández Rodríguez, Madrid, Gredos, 2014, I, pp. 843-1010.

Vega, Lope de, El casamiento en la muerte, ed. Luigi Giuliani, en Comedias de Lope de Vega. Parte I, Lleida, Milenio/Universitat Autònoma de Barcelona, 1997, II, pp. 1149-1276.

Vega, Lope de, El castigo sin venganza, ed. del grupo de investigación Prolope, Barcelona, Promoción y Publicaciones Universitarias, 2011.

Vega, Lope de, El cerco de Santa Fe, ed. Delmiro Antas, en Comedias de Lope de Vega. Parte I, Lleida, Milenio/Universitat Autònoma de Barcelona, 1997, I, pp. 459-557.

Vega, Lope de, El cordobés valeroso Pedro Carbonero, ed. Alejandro García-Reidy, en Comedias de Lope de Vega. Parte XIV, coord. J. Enrique López Martínez, Madrid, Gredos, 2015, II, pp. 1-199.

Vega, Lope de, El cuerdo loco, ed. Antonio Sánchez Jiménez y Adrián J. Sáez, en Comedias de Lope de Vega. Parte XIV, coord. J. Enrique López Martínez, Madrid, Gredos, 2015, II, pp. 725-909.

Vega, Lope de, El favor agradecido, ed. Donald McGrady, Newark, Juan de la Cuesta, 2013.

Vega, Lope de, El galán de la Membrilla, ed. Luis Sánchez Laílla, en Comedias de Lope de Vega. Parte X, coords. Ramón Valdés y María Morrás, Lleida, Milenio/ Universitat Autònoma de Barcelona, 2010, I, pp. 81-229.

Vega, Lope de, El hijo de Reduán, ed. Gonzalo Pontón, en Comedias de Lope de Vega. Parte I, Lleida, Milenio/Universitat Autònoma de Barcelona, 1997, II, pp. 817-980.

Vega, Lope de, El más galán portugués, Duque de Berganza, ed. Carlos Mota, en Comedias de Lope de Vega. Parte VIII, coord. Rafael Ramos, Lleida, Milenio/ Universitat Autònoma de Barcelona, 2009, I, pp. 429-568.

Vega, Lope de, El mayorazgo dudoso, ed. Guillermo Serés, en Comedias de Lope de Vega. Parte II, coord. Silvia Iriso, Lleida, Milenio/Universitat Autònoma de Barcelona, 1998, I, pp. 549-684.

Vega, Lope de, El molino, ed. Patrizia Campana, en Comedias de Lope de Vega. Parte I, Lleida, Milenio/Universitat Autònoma de Barcelona, 1997, III, pp. 15471686.

Vega, Lope de, El nacimiento de Ursón y Valentín, reyes de Francia, ed. Patrizia Campana y Juan-Ramón Mayol Ferrer, en Comedias de Lope de Vega. Parte I, Lleida, Milenio/Universitat Autònoma de Barcelona, 1997, II, pp. 981-1148. 
Vega, Lope de, El nuevo mundo descubierto por Cristóbal Colón, ed. Luigi Giuliani, en Comedias de Lope de Vega. Parte IV, coords. Luigi Giuliani y Ramón Valdés, Lleida, Milenio/Universitat Autònoma de Barcelona, 2002, I, pp. 175-287.

Vega, Lope de, El padrino desposado, ed. Agustín Sánchez Aguilar, en Comedias de Lope de Vega. Parte II, coord. Silvia Iriso, Lleida, Milenio/Universitat Autònoma de Barcelona, 1998, III, pp. 1693-1822.

Vega, Lope de, El primero Benavides, ed. Silvia Iriso Ariz, en Comedias de Lope de Vega. Parte II, coord. Silvia Iriso, Lleida, Milenio/Universitat Autònoma de Barcelona, 1998, II, pp. 839-1022.

Vega, Lope de, El príncipe despeñado, eds. Andrés Pozo y Guillermo Serés, en Comedias de Lope de Vega. Parte VII, coord. Enrico Di Pastena, Lleida, Milenio/ Universitat Autònoma de Barcelona, 2008, III, pp. 1241-1390.

Vega, Lope de, El sembrar en buena tierra, eds. María Morrás y Xavier Tubau, en Comedias de Lope de Vega. Parte X, coord. Ramón Valdés y María Morrás, Lleida, Milenio/Universitat Autònoma de Barcelona, 2010, II, pp. 1043-1180.

Vega, Lope de, El testimonio vengado, ed. Gerardo Salvador Lipperheide, en Comedias de Lope de Vega. Parte I, Lleida, Milenio/Universitat Autònoma de BarceIona, 1997, III, pp. 1687-1805.

Vega, Lope de, El tirano castigado, ed. Margarita Freixas, en Comedias de Lope de Vega. Parte IV, coord. Luigi Giuliani y Ramón Valdés, Lleida, Milenio/Universitat Autònoma de Barcelona, 2002, III, pp. 1493-1638.

Vega, Lope de, Estefanía la desdichada, ed. Violeta Romero, en Comedias de Lope de Vega. Parte XII, coord. José Enrique Laplana Gil, Madrid, Gredos, 2013, II, pp. 627-827.

Vega, Lope de, La amistad pagada, ed. Victoria Pineda, en Comedias de Lope de Vega. Parte I, Lleida, Milenio/Universitat Autònoma de Barcelona, 1997, III, pp. 1397-1545.

Vega, Lope de, La batalla del honor, ed. Ramón Valdés, en Comedias de Lope de Vega. Parte VI, coords. Victoria Pineda y Gonzalo Pontón, Lleida, Milenio/Universitat Autònoma de Barcelona, 2005, I, pp. 65-292.

Vega, Lope de, La bella malmaridada, ed. Enric Querol Coll, en Comedias de Lope de Vega. Parte II, coord. Silvia Iriso, Lleida, Milenio/Universitat Autònoma de Barcelona, 1998, II, pp. 1175-1389.

Vega, Lope de, La buena guarda, ed. Sònia Boadas, en Comedias de Lope de Vega. Parte XV, coord. Luis Sánchez Laílla, Madrid, Gredos [en prensa].

Vega, Lope de, La burgalesa de Lerma, ed. Roberta Alviti, en Comedias de Lope de Vega. Parte X, coords. Ramón Valdés y María Morrás, Lleida, Milenio/Universitat Autònoma de Barcelona, 2010, III, pp. 1509-1661. 
Vega, Lope de, La corona merecida, ed. Fernando Rodríguez-Gallego, en Comedias de Lope de Vega. Parte XIV, coord. J. Enrique López Martínez, Madrid, Gredos, 2015, I, pp. 583-829.

Vega, Lope de, La dama boba, ed. Marco Presotto, en Comedias de Lope de Vega. Parte IX, coord. Marco Presotto, Lleida, Milenio/Universitat Autònoma de Barcelona, 2007, III, pp. 1293-1466.

Vega, Lope de, La doncella Teodor, ed. Julián González-Barrera, en Comedias de Lope de Vega. Parte IX, coord. Marco Presotto, Lleida, Milenio/Universitat Autònoma de Barcelona, 2007, I, pp. 165-302.

Vega, Lope de, La fuerza lastimosa, ed. Montgrony Alberola, en Comedias de Lope de Vega. Parte II, coord. Silvia Iriso, Lleida, Milenio/Universitat Autònoma de Barcelona, 1998, I, pp. 69-243.

Vega, Lope de, La hermosa Ester, ed. José Aragüés, en Comedias de Lope de Vega. Parte XV, coord. Luis Sánchez Laílla, Madrid, Gredos [en prensa].

Vega, Lope de, La mayor virtud de un rey, ed. José Cano Navarro, en La vega del Parnaso, dirs. Felipe B. Pedraza Jiménez y Pedro Conde Parrado, Cuenca, Ediciones de la Universidad de Castilla-La Mancha, 2015, I, pp. 391-535.

Vega, Lope de, La noche toledana, ed. Agustín Sánchez Aguilar, en Comedias de Lope de Vega. Parte III, coord. Luigi Giuliani, Lleida, Milenio/Universitat Autònoma de Barcelona, 2002, pp. 57-251.

Vega, Lope de, La ocasión perdida, ed. Enrico Di Pastena, en Comedias de Lope de Vega. Parte II, coord. Silvia Iriso, Lleida, Milenio/Universitat Autònoma de Barcelona, 1998, I, pp. 245-395.

Vega, Lope de, La prueba de los amigos, ed. Henryk Ziomek, Athens, University of Georgia Press, 1973.

Vega, Lope de, La quinta de Florencia, ed. Bienvenido Morros Mestres, en Comedias de Lope de Vega. Parte II, coord. Silvia Iriso, Lleida, Milenio/Universitat Autònoma de Barcelona, 1998, III, pp. 1559-1691.

Vega, Lope de, La traición bien acertada, eds. Agustín Sánchez Aguilar y Nil Santiáñez-Tió, en Comedias de Lope de Vega. Parte I, Lleida, Milenio/Universitat Autònoma de Barcelona, 1997, II, pp. 697-816.

Vega, Lope de, La viuda valenciana, ed. Rafael Ramos, en Comedias de Lope de Vega. Parte XIV, coord. J. Enrique López Martínez, Madrid, Gredos, 2015, I, pp. 831-999.

Vega, Lope de, Las bizarrías de Belisa, ed. Katerina Vaiopoulos, en La vega del Parnaso, dirs. Felipe B. Pedraza Jiménez y Pedro Conde Parrado, Cuenca, Ediciones de la Universidad de Castilla-La Mancha, 2015, I, pp. 611-742.

Vega, Lope de, Las ferias de Madrid, ed. Donald McGrady, Newark, Juan de la Cuesta, Delaware, 2007. 
Vega, Lope de, Los donaires de Matico, ed. Marco Presotto, en Comedias de Lope de Vega. Parte I, Lleida, Milenio/Universitat Autònoma de Barcelona, 1997, I, pp. 115-254.

Vega, Lope de, Los melindres de Belisa, ed. Jorge León, en Comedias de Lope de Vega. Parte IX, coord. Marco Presotto, Lleida, Milenio/Universitat Autònoma de Barcelona, 2007, III, pp. 1467-1600.

Vega, Lope de, Los Ponces de Barcelona, ed. Marcella Trambaioli, en Comedias de Lope de Vega. Parte IX, coord. Marco Presotto, Lleida, Milenio/Universitat Autònoma de Barcelona, 2007, III, pp. 1053-1154.

Vega, Lope de, Quien más no puede, ed. Laura Naldini, Kassel, Reichenberger, 2001.

Vega, Lope de, Santiago el verde, ed. Francisco Sáez Raposo, en Comedias de Lope de Vega. Parte XIII, coord. Natalia Fernández Rodríguez, Madrid, Gredos, 2014, II, pp. 329-566.

Wilder, Thornton, «New Aids Toward Dating the Early Plays of Lope de Vega», en Varia variorum. Festgabe für Karl Reinhardt, Münster/Köln, Böhlau Verlag, 1952, pp. 194-200.

Wilder, Thornton, «Nuevos instrumentos para fechar las comedias tempranas de Lope de Vega», en Lope en 1604, coord. Xavier Tubau, Lleida, Prolope/UAB/ Milenio, 2004, pp. 189-196.

Zugasti, Miguel, «Autoridad textual y piratería, con sombras de memorión al fondo, en las dos primeras ediciones de El poder de la amistad (1654), de Agustín Moreto», Boletín de la Real Academia Española, 303, 2011, pp. 169-191. 
